Published by LPMP Imperium

Journal homepage: https:/ / ejournal.imperiuminstitute.org/ index.php/ BERDAYA

\title{
Digital Entrepreneurial Marketing: Strategi Bisnis UKM dalam Mengatasi Pandemi Covid 19
}

\author{
Siti Nurjanah*, Triyono A rief Wahyudi \\ Magister Manajemen, Fakultas Bisnis dan Komunikasi, \\ Institut Teknologi dan Bisnis Kalbis
}

\section{ABST RACT}

This activity aims to provide knowledge and motivation to local businesses in the face of the Covid-19 pandemic. In the midst of the pandemic, many business actors in East Belitung are losing money due to Covid-19. A number of business actors have stopped production because there is no demand from consumers. Consumers are more turning to the primary sector to meet their daily needs. Seeing this condition, the executor deems it necessary to hold Community Service activities.

The method used in this activity is in the form of training and training on digital entrepreneurship marketing. Participants are given training with activities using online learning method of providing material and followed by a question and answer session and practice / practice; giving working papers that are filled in according to the real conditions of the participants. Participants in the activity are M SM E players who are in $M$ anggar D istrict, East Belitung Regency. This group is part of an effort to develop local community welfare
Keywords

digital entrepreneurial

marketing, business strategy

\section{Article History}

Received 20 Oct 2020 / A ccepted 10 Dec 2020/ First Published: 30 Dec 2020

\section{To cite this article}

Nurjanah, S., \& Wahyudi, T. (2020). Digital Entrepreneurial Marketing: Strategi Bisnis UKM dalam Mengatasi Pandemi COVID-19. BERDAYA: Jurnal Pendidikan Dan Pengabdian Kepada M asyarakat, 2(3), 125-132.

DOI: $10.36407 /$ berdaya.v2i3.272

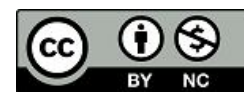

(C) 2020. This open access article is distributed under a CreativeCommons Attribution (CC-BY-NC) 4.0license 
ABSTRAK

Kegiatan ini bertujuan untuk memberikan pengetahuan serta motivasi kepada pelaku usaha setempat dalam menghadapi pandemi Covid-19. Di tengah pandemi, banyak pelaku usaha di Belitung Timur yang merugi akibat Covid-19. Sejumlah pelaku usaha menghentikan produksinya karena tidak adanya permintaan dari konsumen. Konsumen lebih beralih kepada sektor primer untuk memenuhi kebutuhan sehari-hari. Melihat kondisi tersebut, pelaksana memandang perlu untuk mengadakan kegiatan Pengabdian Kepada Masyarakat.

Metode yang digunakan dalam kegiatan ini adalah dalam bentuk pelatihan dan training tentang Pemasaran kewirausahaan digital. Peserta diberikan pelatihan dengan kegiatan dengan metode online learning, pemberian materi dan dilanjutkan dengan sesi tanya jawab dan Latihan/ Praktek; pemberian kertas kerja yang diisi sesuai dengan kondisi riil peserta. Peserta kegiatan yaitu pelaku UMKM yang berada di Kecamatan Manggar, Kabupaten Belitung Timur. Kelompok ini merupakan bagian dari upaya pembangunan kesejahteraan masyarakat setempa
Profil Penulis

Siti Nurjanah

Triyono Arief Wahyudi
Kata Kunci :

Pemasaran kewirausahaan digital, strategi bisnis
Magister Manajemen, Fakultas Bisnis dan Komunikasi, Institut Teknologi dan Bisnis Kalbis J. Pulomas Selatan Kav.22 Jakarta

\section{Penulis korespondensi:}

Siti Nurjanah

email: siti.nurjanah@kalbis.ac.id

\section{PENDAHULUAN}

Pandemi Covid-19 yang awalnya muncul di Tiongkok pada akhir tahun 2019 hingga menyebar ke seluruh dunia membawa berbagai dampak, baik dari segi ekonomi, bisnis hingga keamanan. Lebih khusus, apabila dilihat dari segi ekonomi, pandemi Covid-19 menimbulkan gelombang pemutusan hubungan kerja dan banyak perusahaan harus gulung tikar akibat rendahnya daya beli masyarakat. Tidak hanya itu, pandemi Covid-19 menimbulkan runtuhnya berbagai sektor industri serta terhambatnya distribusi sebagai akibat banyaknya wilayah yang menerapkan pembatasan produk dari luar negeri.

Di Indonesia, Covid-19 mulai merebak sejak 2 Maret 2020 dan langsung ditetapkan sebagai "bencana nasional" oleh Presiden Joko Widodo. Dengan pertambahan kasus positif yang semakin bertambah dari hari ke hari membuat berbagai sektor ekonomi pun terkena dampaknya. Pakpahan (2020) mengatakan bahwa "ada tiga implikasi bagi Indonesia terkait pandemi COVID-19" yaitu pada sektor pariwisata, perdagangan dan investasi. Ditambahkan Pakpahan, sektor Usaha Mikro, Kecil dan Menengah (UMKM) juga "mengalami dampak yang serius", tidak hanya pada aspek jumlah produksi dan nilai perdagangan. Pandemi Covid-19 juga berakibat pada meningkatnya jumlah tenaga kerja yang harus kehilangan pekerjaan. 
Di tengah pandemi Covid-19, pengusaha dituntut untuk mampu bertahan serta menangkap peluang usaha. Kecermatan dan strategi yang dibutuhkan setiap pengusaha guna menekan dampak yang ditimbulkan sebagai akibat dari pandemi. Lebih lanjut, strategi dalam bertahan dan menangkap peluang usaha dapat dilihat dari segi pengelolaan keuangan serta bagaimana melakukan pemasaran untuk menjangkau pelanggan.

Belitung Timur merupakan salah satu wilayah yang menjadi tujuan wisata masyarakat. Potensi pariwisata yang sangat tinggi di Belitung Timur muncul dari adanya lokasi wisata Kampung Ahok dan Laskar Pelangi. Tidak hanya itu, Belitung Timur juga memiliki banyak warung kopi. Banyaknya warung kopi membuat kopi Belitung Timur menjadi sangat terkenal.

Di tengah pandemi, banyak pelaku usaha di Belitung Timur yang merugi akibat Covid-19. Sejumlah pelaku usaha menghentikan produksinya karena tidak adanya permintaan dari konsumen. Konsumen lebih beralih kepada sektor primer untuk memenuhi kebutuhan sehari-hari. Melihat kondisi tersebut, pelaksana memandang perlu untuk mengadakan kegiatan Pengabdian Kepada Masyarakat guna memberikan pengetahuan serta motivasi kepada pelaku usaha setempat dalam menghadapi pandemi Covid-19.

Sasaran dalam kegiatan ini adalah kelompok pelaku UMKM yang berada di Kecamatan Manggar, Kabupaten Belitung Timur. Kelompok ini merupakan bagian dari upaya pembangunan kesejahteraan masyarakat setempat. Manfaat kegiatan ini adalah pelaku UMKM merasa terbantu dengan diberikan pengetahuan tentang pemasaran kewiraushaan digital. Pelaku UMKM merasa termotivasi untuk bangkit dari keterpurukannya sel ama masa covid. pelaku UMKM akan mendapatkan pendampingan oleh Tim Kalbis Institut sampai mereka menjadi UMKM yang mandiri

\section{Sasaran Kegiatan}

Sasaran dalam kegiatan ini adalah pelaku UMKM yang berada di kecamatan Manggar Kabupaten Belitung Timur sehingga diharapkan mereka mampu memiliki pengetahuan serta motivasi dalam menghadapi pandemi Covid-19. Pelaku UMKM di Belitung Timur juga diharapkan memiliki pemahaman tentang bagaimana menjalankan pemasaran secara digital.

\section{Masalah yang ingin dipecahkan}

Berdasarkan hasil observasi dan wawancara awal dengan pihak mitra, pelaksana melihat bahwa pelaku UMKM memiliki beberapa kendala. Kendala pertama yang dihadapi adalah terkait dalam melakukan distribusi atas produk yang mereka produksi. Sejumlah pelaku UMKM menggandeng pihak lain dalam melakukan distribusi terhadap produknya, seperti kantin sekolah, toko dll. Dengan demikian, saat pandemi Covid-19 terjadi, pelaku usaha harus mencari alternatif lain dalam mendistribusikan produknya.

\section{MATERI DAN METODE}

\section{Materi}

Pemasaran kewirausahaan didefinisikan sebagai tindakan efektif atau adaptasi teori pemasaran dengan kebutuhan khusus usaha kecil (Becherer et al., 2006). Sementara beberapa penulis berpendapat bahwa itu dapat digambarkan sebagai aktivitas pemasaran dengan pola pikir kewirausahaan, terlepas dari ukuran atau usia perusahaan (Kraus et al., 2010), secara luas diterima bahwa konsep tersebut sangat sesuai dengan konteks bisnis kecil (Jones 
dan Rowley, 2011; Gilmore dan Carson, 1991). Menurut Bjerke dan Hultman (2002), pemasaran kewirausahaan adalah pemasaran perusahaan kecil yang tumbuh melalui kewirausahaan. Karena UKM menghadapi beberapa keterbatasan seperti memiliki sedikit pelanggan utama, sumber daya terbatas dalam bisnis dan pemasaran; pengaruh wirausaha, kurangnya struktur organisasi formal atau sistem komunikasi formal (Jones dan Rowley, 2011; Kolabi et al., 2011), pemasaran kewirausahaan menjadi lebih sesuai untuk usaha kecil dan menengah.

Kraus et al. (2010) mengidentifikasi dua perspektif dalam definisi pemasaran kewirausahaan. Yang pertama mendefinisikan pemasaran kewirausahaan sebagai pemasaran untuk usaha kecil atau baru dengan menekankan aspek kuantitatif perusahaan, dan yang kedua mendefinisikan pemasaran kewirausahaan sebagai pemasaran dengan jiwa kewirausahaan (pemasaran oleh pengusaha) dengan menyoroti aspek kualitatif pemasaran kewirausahaan. Kemudian dikemukakan bahwa kedua upaya untuk mendefinisikan pemasaran kewirausahaan mungkin merupakan dua sisi dari mata uang yang sama, karena karakteristik kualitatif (kecil dan baru) tampaknya menjadi konteks yang mendukung kegiatan pemasaran yang didorong ol eh kewirausahaan, yaitu inovatif, berisiko- berorientasi dan semangat proaktif (Kraus et al., 2010).

Asosiasi Pemasaran Amerika (definisi AMA tentang pemasaran dan definisi kewirausahaan, kraus et al. (2009) mengajukan definisi baru pemasaran kewirausahaan: "kewirausahaan pemasaran adalah fungsi organisasi dan serangkaian proses untuk menciptakan, mengkomunikasikan, dan memberikan nilai kepada pelanggan dan untuk mengelola hubungan pelanggan dengan cara yang menguntungkan organisasi dan pemangku kepentingannya, dan yang dicirikan oleh inovasi, pengambilan risiko, proaktif, dan mungkin dilakukan tanpa sumber daya yang saat ini dikendalikan. "Morris et al. (2002) mengembangkan tujuh dimensi inti dari pemasarankewirausahaan: proaktif, pengambilan risiko yang diperhitungkan, inovasi, fokus peluang, pemanfaatan sumber daya, intensitas pelanggan, dan penciptaan nilai.

\section{Lokasi Kegiatan}

Lokasi dalam kegiatan ini adalah Kecamatan Manggar berada di pusat kota Kabupaten Belitung Timur. Sebagai pusat kota, Kantor Bupati dan Wakil Bupati berkedudukan di Kecamatan Manggar. Lebih lanjut, Kecamatan Manggar berbatasan langsung dengan beberapa daerah lainnya di Belitung Timur. Di bagian utara, Kecamatan Manggar berbatasan dengan Kecamatan Kelapa Kampit dan Damar; di selatan berbatasan dengan Laut Jawa; di barat berbatasan dengan Kecamatan Simpang Renggiang dan Gantung; serta di timur berbatasan dengan Selat Karimata.

\section{Peserta}

Peserta dalam kegiatan ini adalah kelompok pelaku UMKM yang berada di Kecamatan Manggar, Kabupaten Belitung Timur. Kelompok ini merupakan bagian dari upaya pembangunan kesejahteraan masyarakat setempat 


\section{Prosedur dan M etode}

Prosedur dalam pelaksanaan kegiatan ini adalah dengan melakukan observasi terhadap kebutuhan dari mitra, pelaksanaan observasi dengan melakukan pertemuan antara pihak Pemda yang diwakili oleh aparat Pemda, kecamatan Belitung Timur serta pelaku UMKM. Observasi yang dilakukan mendapatkan identifikasi dari permasalahan mitra. Metode yang digunakan dalam kegiatan pengabdian ini berupa pemberian materi berupa workshop kepada seluruh anggota UMKM yang berada di Kecamatan Manggar, Belitung Timur.

\section{HASIL DAN PEMBAHASAN}

Hasil dan pembahasan memuat uraian mengenai pelaksanaan kegiatan, berbagai kesulitan yang dihadapi di lapangan, dan evaluasi kegiatan. Lengkapi dengan dokumentasi kegiatan.

\section{Pelaksanaan Kegiatan}

Pelaksanaan kegiatan dilakukan melalui observasi terlebih dahulu untuk mengetahui permasalah mitra. Mitra dalam kegiatan ini adalah:

1. Pemerintah Daerah Kabupaten Belitung Timur

2. Pihak Kecamatan Manggar Kabupaten Belitung Timur

3. Pihak Akademi Manajemen Belitung Timur

4. Mitra UMKM yang berada di Kecamatan Manggar

Kegiatan ini dilaksanakan pada pelaku UMKM yang berada di Kecamatan Manggar, Belitung Timur secara virtual menggunakan aplikasi Zoom. Pelaksanaan PKM dilakukan pada tanggal 25 dan 26 Juni 2020. Tahap-tahap pelaksanaan kegiatan PKM adalah:

1. Dilakukan program sosial isasi bagaimana bertahan ditengah pandemi covid 19;

2. Pelatihan untuk meningkatkan pengetahuan dan pemahaman digital entrepreneurial marketing

\section{Evaluasi Kegiatan}

Setelah proses pelaksanaan kegiatan, maka diadakan evaluasi untuk melihat apakah pelatihan yang diberikan memiliki indikator keberhasilan. Evaluasi yang dilakukan adalah denganmenerima feedback dari pihak yang menjadi mitra kami. Pelaksanaan PKM dijalankan secara virtual dikarenakan kondisi pandemic Covid. Pelatihan dilaksanakan secara virtual dengan menggunakan akun zoom. Indikator keberhasilan dalam pelatihan ini dapat dilihat dari antusiasme mitra aktif dalam mengikuti pelatihan, serta keatifan mitra dalam sesi diskusi Tanya jawab, yang dilaksanakan dalam pelatihan ini. Keberlanjutan usaha yang sudah dilakukan diharapkan dapat diaplikasikan metode yang diajarkan dalam pelatihan, Upaya lain yang kita lakukan adalah dengan memberikan pendampingan terhadap para pelaku UMKM, sehingga mereka bisa menjadi UMKM yang mandiri.

Peran Serta M itra dalam Kegiatan (Keaktifan)

Peran serta mitra dalam kegiatan ini adalah sebagai penyedia tempat pelatihan, yang dilaksanakan di Aula Kecamatan Manggar - Kabupaten Belitung Timur. Mitra sangat antusias dan terbuka dalam menerima beberapa kali kunjungan sebelum akhirnya pelaksanaan kegiatan 
dilaksanakan, mitra berharap kegiatan seperti ini tidak hanya dilaksanakan sekali aja, tapi berkelanjutan dan dilakukan oleh pendapingan oleh pihak Kalbis Institut.

Peranan dan tugas mitra dalam kegiatan PKM adalah

1. Pemerintah Daerah Kabupaten Belitung Timur merupakan mitra yang menginisiai pelaksanaan PKM Belitung Timur

2. Pihak Kecamatan Manggar Kabupaten Belitung Timur merupakan mitra yang memberikan fasilitas tempat, fasilitas sarana dan prasarana lain (spt zoom dll) sehingga pelaksanaan PKM ini bisa tercapai

3. Pihak Akademi Manajemen Belitung Timur merupakan mitra perguruan tinggi lokal yang berada di Kabupaten Belitung Timur yang menfasilitasi pelaksanaan pelaksanaan PKM ini

4. Mitra UMKM yang berada di Kecamatan Manggar sebagai peserta PKM yang menerima materi pelatihan dari Kami.

Produk/Kegiatan yang Dinilai Bermanfaat

Berdasarkan hasil diskusi bersama mitra PKM, kegiatan yang dinilai sangat bermanfaat bagi mereka dari pelatihan yang diberikan, antara lain:

1. Memberikan motivasi mereka untuk tetap bertahan pada masa pandemic

2. Memberikan insight kepada mereka untuk mendapatkan inovasi inovasi dalam mengembangkan produk mereka

3. Mencari solusi terhadap permasalahan yang mereka hadapi

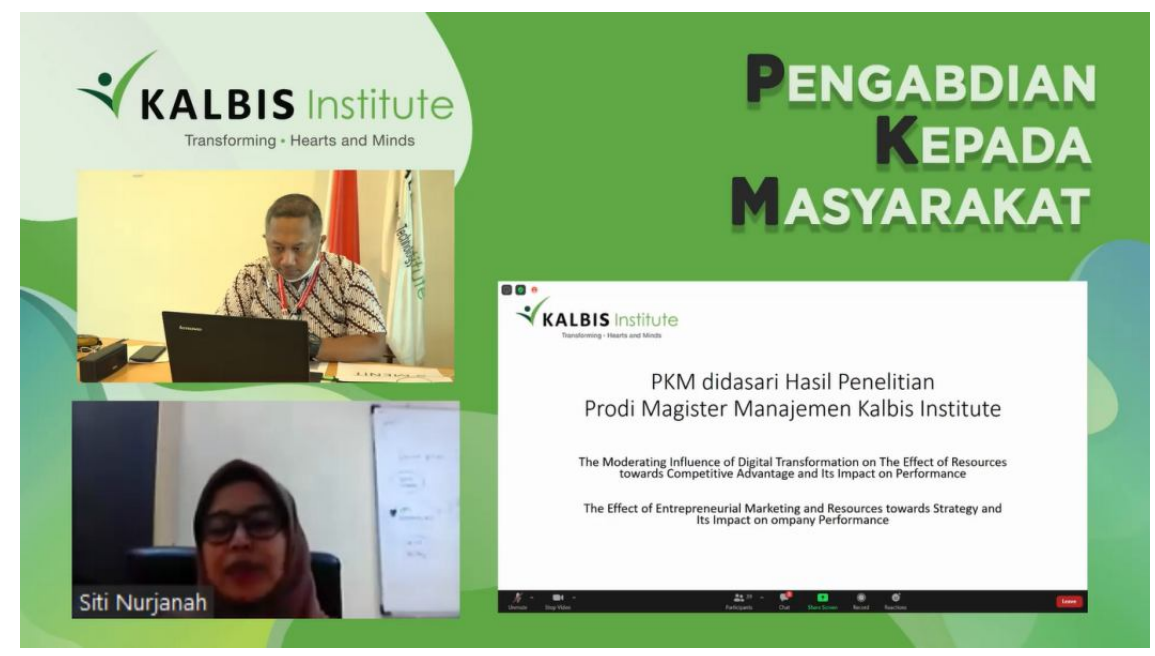

\section{Gambar 1.}

Pemberian M ateri

Ceramah

Sumber:

Dokumentasi Tim

Pelaksana (2020)

\section{KESIMPULAN}

\section{Kesimpulan}

Pelaksanaan kegiatan PKM berjalan lancar, manfaat yang diperoleh oleh UMKM Kecamatan Manggar adalah :

1. Pelaku UMKM merasa terbantu dengan diberikan pengetahuan pengelolaan UMKM

2. Pelaku UMKM merasa termotivasi untuk bangkit dari keterpurukannya selama masa covid 
Siti Nurjanah \& Triyono Arief Wahyudi

The digital entrepreneurial marketing, business strategy

3. Pelaku UMKM akan mendapatkan pendampingan oleh Tim Kalbis Institut sampai mereka menjadi UMKM yang mandiri

\section{Saran kegiatan Lanjutan}

Kegiatan selanjutnya dapat dilaksanakan di lokasi yang sama dengan mitra yang sama pula, karena mi tra berharap kegiatan ini berlanjut, beberapa usulan yang dapat dilakukan:

Memberikan pendampingan kepada para pelaku UMKM sampai mereka mampu untuk mandiri menjalankan usaha mereka.

\section{REFERENSI}

Becherer, R. C., Haynes, P. J., and Helms, M. M. (2008), An Exploratory Investigation of Entrepreneurial Marketing, Journal of Business and Entrepreneurship, 20, 44-64.

Bjerke, B. and Hultman, C.M. (2002), Entrepreneurial Marketing: The Growth of Small Firms in the New Economic Era, Edward Elgar Publishing Limited, UK.

Gilmore, A. and Carson, D. (1991), Entrepreneurial Marketing by Networking, New England Journal of Entrepreneurship, 12(2), pp.31-38.

Jones, R and Rowley, J. (2011), Entrepreneurial Marketing in Small Businesses: a Conceptual Exploration, International Small Business Journal, 29(1), pp.25-36.

Kolabi, A.M., Hosseini, H. K., Mehrabi, R. and Salamzadeh, A. (2011), Developing Entrepreneurial Marketing Mix: Case Study of Entrepreneurial Food Enterprises in Iran, Journal of Knowledge Management Economics and Information Technology, (5), 1-17.

Kraus, S., Harms, R. And Fink, M. (2010), Entrepreneurial Marketing: Moving beyond Marketing in New Ventures, International Journal of Entrepreneurship and Innovation Management, 11(1), pp.19-34.

Morris, M.H., Schindehutte, M. and LaForge, R.W. (2002), Entrepreneurial Marketing: A construct for Integrating Emerging Entrepreneurship and Marketing Perspectives, Journal of Marketing Theory Practice, 10(4), pp.1-19. 


\section{FUNDING}

Kegiatan ini merupakan bagian dari program Pengabdian Kepada Masyarakat yang didanai oleh Fakultas Bisnis dan Komunikasi .tahun 2020, Pemda Belitung Timur 2020 sertaAkademi Manajemen Belitung

\section{COMPETING INTEREST}

Tidak ada konflik kepentingan yang bersifat pribadi, profesional, atau finansialuntuk diungkapkan.

\section{A bout The A uthors}

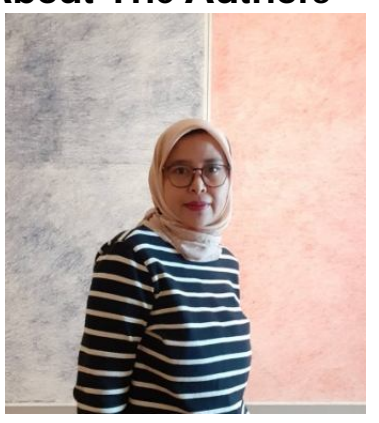

Dr.Siti Nurjanah, SE, MM adalah seorang dosen pada program studi Magister Manajemen Institut Teknologi dan Bisnis Kalbis dan saat ini menjabat sebagai Deputy Warek 1 di Institut Teknologi dan Bisnis Kalbis. Pengalaman cukup banyak sebagai pengelola pendidikan dengan berbagai jabatan yang diduduki. Pengalaman selain sebagai seorang dosen, pengelola pendidikan, peneliti juga sebagai seorang entrepreneur yang aktif dalam pengembangan usaha UKM. Topik penelitian yang beliau geluti diantaranya entrepreneurial marketing, social marketing, Change behavior dll.Penulis dapat dihubungi melalui email: siti.nurjanah@kalbis.ac.id 